\title{
Laparoscopic hepatectomy in cirrhotic patients with hepatocellular carcinoma: technical aspects and potential benefits
}

\author{
Osamu Itano, Takuya Minagawa, Yuko Kitagawa
}

Department of Surgery, Keio University School of Medicine, Tokyo 160-8582, Japan

\author{
Address for correspondence: \\ Dr. Osamu Itano, Department of Surgery, Keio University School of Medicine, 35 Shinanomachi, Shinjuku-ku, Tokyo 160-8582, Japan. \\ E-mail: itano@z8.keio.jp
}

Received: 29-01-2015, Accepted: 03-03-2015

\section{INTRODUCTION}

Surgical procedures are considered more challenging in cirrhotic patients with hepatocellular carcinoma (HCC) than in non-cirrhotic patients, because of the former's high morbidity and mortality following surgery. ${ }^{[1]}$ In open liver surgery, the extremely long incision required for mobilization and resection of the liver can result in significant intraoperative blood loss or postoperative intractable ascites, followed by reduced collateral circulation in the abdominal wall and ligaments around the liver. These complications may progress to postoperative hepatic failure in some patients. ${ }^{[2]}$

Innovations in technology and surgical skills for hepatectomy have been applied to minimize postoperative complications. Some of these are as follows: (1) sophisticated instruments for liver transection, such as ultrasonic aspirators and high-energy devices; (2) inflow and outflow vascular control, such as inflow occlusion of the portal triad (Pringle maneuver), selective hepatic vascular occlusion, and total hepatic vascular exclusion; ${ }^{[3]}(3)$ an anterior approach without liver mobilization in order to prevent liver compression and tumor rupture; ${ }^{[4]}$ and (4) a liver-hanging maneuver to minimize bleeding in the deeper parenchymal plane and to guide the direction of the parenchymal transaction. ${ }^{[5]}$

\begin{tabular}{|l|c|}
\hline \multicolumn{2}{|c|}{ Access this article online } \\
\hline \multirow{2}{*}{ Website: } & Quick Response Code \\
http://www.hrjournal.net/ & \\
\hline & DOI: \\
10.4103/2394-5079.153786 & \\
&
\end{tabular}

Since the late 1990s, laparoscopic surgery has gained popularity, resulting in a paradigm shift in liver surgery. Laparoscopic hepatectomy is thought to be a less-invasive procedure than open hepatectomy. ${ }^{[6]}$ The benefits of laparoscopic hepatectomy may be particularly advantageous for reducing intraoperative blood loss and retaining postoperative ascites. In matched-paired comparative studies and a comprehensive meta-analysis, laparoscopic hepatectomy was found to have several perioperative advantages with no differences in oncological outcomes. ${ }^{[7-11]}$ Recent technological advances and accumulation of surgical experience have gradually expanded the indications for laparoscopic hepatectomy to include treatment for HCC. Laparoscopic hepatectomy has now been performed even in cirrhotic patients with HCC. There are several tips and techniques for safely performing laparoscopic resection on the cirrhotic liver, as described below.

\section{LAPAROSCOPIC LIVER MOBILIZATION}

We strongly recommend laterally dissecting the coronary and triangular ligaments, after identifying the supra-hepatic inferior vena cava (IVC) ("medial-to-lateral approach"). ${ }^{\text {[12] }}$ Dissection of the cranial ligamentous attachment using the medial-to-lateral approach helps avoid injuries to the IVC and hepatic veins as well as to potential collateral vessels at the lateral edges of the triangular ligament, which can be difficult to control in some cirrhotic patients. Achieving careful ligation of the short hepatic veins with sealing devices and/or clips under a clear vision is essential for liver mobilization. Surgeons need to utilize gravity and retraction effectively to provide a clear view and avoid blind procedures. Moreover, after the surgeon acquires adequate experience with the technique, laparoscopic liver mobilization provides 
better visualization and a more precise procedure than does open surgery.

Liver mobilization itself may result in postoperative refractory ascites, considering the destruction of collateral blood and lymphatic flow. ${ }^{[13]}$ In laparoscopic surgery, depending on the location of the tumor, liver rotation by gravity and gentle manipulation often enables liver resection without liver mobilization.

\section{LAPAROSCOPIC LIVER TRANSECTION TECHNIQUE (SUPERFICIAL PRE-COAGULATION, SEALING, AND TRANSECTION METHOD)}

Liver transection is the most challenging aspect of hepatectomy in terms of bleeding. Pre-coagulation of the superficial parenchyma using a radiofrequency ablation device is useful for controlling intraoperative bleeding. ${ }^{[14]}$ We introduced an original laparoscopic liver transection technique, the superficial pre-coagulation, sealing, and transection method. ${ }^{[15]}$ This method consists of four steps: Superficial pre-coagulation from the liver surface using a needle-type electrode with the VIO 300 D soft-coagulation system (ERBE Elektromedizin, Tübingen, Germany); exposure of vessels and bile ducts with an ultrasonic aspirator; sealing of the vessels and bile ducts with energy devices; and transection of the liver parenchyma. In this method, bleeding can be well controlled even during transection, which enables bloodless transection without inflow and outflow vascular occlusion. In our previous report, this method yielded good results for patients with deteriorated liver function. ${ }^{[15]}$ The other benefit of this method is its eco-friendly nature. All devices used in this method are reusable by autoclave sterilization. This simple, safe, and eco-friendly transection method has the potential to become the standard method of laparoscopic liver transection.

\section{HARNESS TRACTION TECHNIQUE (HARNESS)}

We also developed a novel method for controlling the transection plane, which we refer to as the "Harness Traction Technique (HARNESS)", for safe and precise dissection in pure laparoscopic hepatectomy, especially anatomical resection. The idea for this technique was originally derived from the liver-hanging maneuver. ${ }^{[5]}$ The characteristics of HARNESS, which are different from those of the open hanging maneuver, includes the creation of a groove all along the transection line and tying tape along the groove. This technique enables maintenance of a precise transection plane and control of the location and direction of the dissection plane freely in the abdominal cavity, similar to a horse being controlled by traction of the harness, which results in minimized bleeding, movement of the transection point to the appropriate position, and creation of good tension for parenchymal transection at the transection point. The original hanging maneuver can only be applied in right hemihepatectomy and extended posterior sectionectomy; however, HARNESS can be applied to various kinds of laparoscopic hepatectomies, even those without a natural hook for the tape, such as posterior sectionectomy, anterior sectionectomy, and partial hepatectomy.

The described techniques have resulted in good clinical outcomes, as described in our previous reports. ${ }^{[12,15]}$ These less-invasive and systematic procedures have the potential to prevent postoperative hepatic failure. Keeping these points in mind ensures that laparoscopic hepatectomy becomes a simple and safe procedure, even for cirrhotic patients with HCC. Furthermore, laparoscopic hepatectomy is associated with fewer postoperative adhesions than conventional open hepatectomy. For the cirrhotic liver, which is a well-known precancerous condition requiring multimodal treatment, this benefit could enable any future surgical treatments to be performed much more easily in case of recurrence. For tumors on the liver surface, the procedure also carries a lower risk of peritoneal dissemination than radiofrequency ablation. With regard to both surgical and oncological aspects, these advantages make laparoscopic hepatectomy ideal as a bridging therapy for curative liver transplantation..$^{[6,16]}$

\section{REFERENCES}

1. Ziser A, Plevak DJ, Wiesner RH, Rakela J, Offord KP, Brown DL. Morbidity and mortality in cirrhotic patients undergoing anesthesia and surgery. Anesthesiology 1999;90:42-53.

2. Kanazawa A, Tsukamoto T, Shimizu S, Kodai S, Yamazoe S, Yamamoto S, Kubo S. Impact of laparoscopic liver resection for hepatocellular carcinoma with F4-liver cirrhosis. Surg Endosc 2013;27:2592-7.

3. Van Gulik TM, de Graaf W, Dinant S, Busch OR, Gouma DJ. Vascular occlusion techniques during liver resection. Dig Surg 2007;24:274-81

4. Lai EC, Fan ST, Lo CM, Chu KM, Liu CL. Anterior approach for difficult major right hepatectomy. World J Surg 1996;20:314-7.

5. Belghiti J, Guevara OA, Noun R, Saldinger PF, Kianmanesh R. Liver hanging maneuver: a safe approach to right hepatectomy without liver mobilization. J Am Coll Surg 2001;193:109-11.

6. Kaneko H, Tsuchiya M, Otsuka Y, Yajima S, Minagawa T, Watanabe M, Tamura A. Laparoscopic hepatectomy for hepatocellular carcinoma in cirrhotic patients. J Hepatobiliary Pancreat Surg 2009;16:433-8.

7. Memeo R, de'Angelis N, Compagnon P, Salloum C, Cherqui D, Laurent A, Azoulay D. Laparoscopic vs. open liver resection for hepatocellular carcinoma of cirrhotic liver: a case-control study. World J Surg 2014;38:2919-26.

8. Kim SJ, Jung HK, Lee DS, Yun SS, Kim HJ. The comparison of oncologic and clinical outcomes of laparoscopic liver resection for hepatocellular carcinoma. Ann Surg Treat Res 2014;86:61-7.

9. Cheung TT, Poon RT, Yuen WK, Chok KS, Jenkins CR, Chan SC, Fan ST, Lo CM. Long-term survival analysis of pure laparoscopic 
versus open hepatectomy for hepatocellular carcinoma in patients with cirrhosis: a single-center experience. Ann Surg 2013;257:506-11.

10. Truant S, Bouras AF, Hebbar M, Boleslawski E, Fromont G, Dharancy S, Leteurtre E, Zerbib P, Pruvot FR. Laparoscopic resection vs. open liver resection for peripheral hepatocellular carcinoma in patients with chronic liver disease: a case-matched study. Surg Endosc 2011;25:3668-77.

11. Mirnezami R, Mirnezami AH, Chandrakumaran K, Abu Hilal M, Pearce NW, Primrose JN, Sutcliffe RP. Short- and long-term outcomes after laparoscopic and open hepatic resection: systematic review and meta-analysis. HPB (Oxford) 2011;13:295-308.

12. Ikoma N, Itano O, Oshima G, Kitagawa Y. Laparoscopic liver mobilization: tricks of the trade to avoid complications. Surg Laparosc Endosc Percutan Tech 2015;25:e21-3.

13. Morise Z, Kawabe N, Kawase J, Tomishige H, Nagata H, Ohshima H, Arakawa S, Yoshida R, Isetani M. Pure laparoscopic hepatectomy for hepatocellular carcinoma with chronic liver disease. World J Hepatol 2013;5:487-95

14. Weber JC, Navarra G, Jiao LR, Nicholls JP, Jensen SL, Habib NA. New technique for liver resection using heat coagulative necrosis. Ann Surg 2002;236:560-3.

15. Itano O, Ikoma N, Takei H, Oshima G, Kitagawa Y. The superficial precoagulation, sealing, and transection method: a "bloodless" and "ecofriendly" laparoscopic liver transection technique. Surg Laparosc Endosc Percutan Tech 2015;25:e33-6.

16. Cherqui D, Laurent A, Tayar C, Chang S, Van Nhieu JT, Loriau J, Karoui M, Duvoux C, Dhumeaux D, Fagniez PL. Laparoscopic liver resection for peripheral hepatocellular carcinoma in patients with chronic liver disease: midterm results and perspectives. Ann Surg 2006;243:499-506.

How to cite this article: Itano O, Minagawa T, Kitagawa Y. Laparoscopic hepatectomy in cirrhotic patients with hepatocellular carcinoma: technical aspects and potential benefits. Hepatoma Res 2015;1:6-8.

Source of Support: Nil. Conflict of Interest: None declared. 